\title{
Article
}

\section{Reuse of Decommissioned Hydrocarbon Wells in Italian Oilfields by Means of a Closed-Loop Geothermal System}

\author{
Martina Gizzi (D), Glenda Taddia *(D) and Stefano Lo Russo \\ Department of Environment, Land and Infrastructure Engineering, Politecnico di Torino, C.so Duca degli \\ Abruzzi 24, 10129 Torino, Italy; martina.gizzi@polito.it (M.G.); stefano.lorusso@polito.it (S.L.R.) \\ * Correspondence: glenda.taddia@polito.it
}

check for updates

Citation: Gizzi, M.; Taddia, G.; Lo Russo, S. Reuse of Decommissioned Hydrocarbon Wells in Italian Oilfields by Means of a Closed-Loop Geothermal System. Appl. Sci. 2021, 11, 2411. https://doi.org/10.3390/ app11052411

Academic Editor: Woochul Kim

Received: 29 January 2021

Accepted: 3 March 2021

Published: 9 March 2021

Publisher's Note: MDPI stays neutral with regard to jurisdictional claims in published maps and institutional affiliations.

Copyright: (c) 2021 by the authors. Licensee MDPI, Basel, Switzerland. This article is an open access article distributed under the terms and conditions of the Creative Commons Attribution (CC BY) license (https:/ / creativecommons.org/licenses/by/ $4.0 /)$.

\begin{abstract}
Geological and geophysical exploration campaigns have ascertained the coexistence of low to medium-temperature geothermal energy resources in the deepest regions of Italian sedimentary basins. As such, energy production based on the exploitation of available geothermal resources associated with disused deep oil and gas wells in Italian oilfields could represent a considerable source of renewable energy. This study used information available on Italian hydrocarbon wells and on-field temperatures to apply a simplified closed-loop coaxial Wellbore Heat Exchanger (WBHE) model to three different hydrocarbon wells located in different Italian oilfields (Villafortuna-Trecate, Val d'Agri field, Gela fields). From this study, the authors have highlighted the differences in the quantity of potentially extracted thermal energy from different analysed wells. Considering the maximum extracted working fluid temperature of $100{ }^{\circ} \mathrm{C}$ and imagining a cascading exploitation mode of the heat accumulated, for Villafortuna 1 WBHE was it possible to hypothesise a multi-variant and comprehensive use of the resource. This could be done using existing infrastructure, available technologies, and current knowledge.
\end{abstract}

Keywords: renewable energy; geothermal energy; mature oilfield; abandoned hydrocarbon well; wellbore heat exchanger

\section{Introduction}

The policy visions of the 2030 UN Agenda for Sustainable Development and the Paris Agreement on Climate Change were both approved by the member states of the UN in 2015 and represent two fundamental contributions that guide the transition towards an economic model that aims not only for profitability but also for social progress and environmental protection. To achieve increased energy efficiency, all nations must change the ways in which they produce and manage natural energy resources in order to create more sustainable and environmentally resilient communities.

The current Italian urban energy paradigm relies heavily on fossil fuels; given the air pollution and resource depletion caused by fossil-fuel use, this is unsustainable. Public and private investments in energy must be increased, especially for innovative technological models that transform the energy system, integrating renewable energy into end-use applications in buildings, transportation and industry.

Geoscience offers solutions to this issue through the development of various options that could encourage decarbonisation and the transition to renewable energy sources at local and regional scales: electricity production from renewable sources, domestic heating/cooling using low-enthalpy geothermal energy resources and larger-scale technologies that target harmful emissions, such as bioenergy production and carbon capture and storage [1].

Geothermal energy is a weather-independent, environmentally friendly and currently available renewable resource; it represents an effective solution for power generation, heating and cooling, and direct-use applications. Specifically, energy production from 
available low- to medium-temperature geothermal resources associated with disused deep oil and gas wells in Italian oilfields has considerable potential. As a renewable energy source, it could solve problems associated with suspended wells near municipalities and allow for longer-term use of hydrocarbon wells, even at the end of their production cycle, which would benefit industry, civil and agriculture districts. According to [2], the variety of possible direct applications of geothermal resources in production districts, together with the corresponding temperature demand, is wide. It includes space heating, industrial uses, swimming pools, horticulture (especially greenhouses) and aquaculture.

Studies have shown that hydrocarbon reservoirs and geothermal energy resources can coexist in sedimentary basin contexts because both have similar reservoir conditions [3-5]. Hydrocarbon resources are generated under specific temperature and pressure conditions in the source rocks, and groundwater is always involved in both the primary migration of oil from the source rock and the secondary migration of oil and gas to the reservoir. Consequently, oil and gas reservoirs in hydrocarbon basins act as geothermal reservoirs.

Sedimentary basins have been explored for both oil and gas extraction purposes, so deep hydrocarbon wells are located in this geological context. Well logs, temperature distribution profiles and reservoir properties, such as depth to basement and geological formation thickness, are generally well known.

Since 1985, 7246 wells have been drilled for hydrocarbon extraction in Italy, 898 of which are located onshore with varying operational statuses [6]. A variety of oil and gas reservoirs have been identified; geological and geophysical exploration campaigns into the deepest regions of such geological contexts have ascertained the coexistence of hydrocarbons and the low- to medium-temperature geothermal energy resources $[7,8]$.

Recent investigations have attempted to assess geothermal potentials, exploring deep geothermal resources in different regions and reconstructing heat flow maps at different depths $[9,10]$.

Additionally, in order to determine heat conductivity values at the regional and local scales, the thermal conductivity of 200 rock samples collected from four different regions of southern Italy (Calabria, Campania, Apulia and Sicily) was investigated by [11], measuring its value in both dry and wet conditions. Morover, in reference [12] it was utilised the framework of the MIUR-2008 project "Geothermal resources of the Mesozoic basement of the Po Basin: groundwater flow and heat transport" to accurately estimate the thermophysical properties of a wide variety of sedimentary and intrasedimentary volcanic rocks from the Po Basin through laboratory measurements of density and porosity.

Since it is stored in subsurface geological formations and associated with hydrocarbons, geothermal energy must be extracted before it can be used. Decommissioned or disused oil and gas wells, especially those in mature oilfields, are good candidates for geothermal heat exploitation and may provide access to subsurface energy resources.

Considering the large number of existing oil wells dismissed every year in Italian fields, various studies have proposed new engineering tools to evaluate the possible use of such thermal resources. In reference [13], it was developed an effective method for doing so through the use of a closed-loop system with associated Wellbore Heat Exchanger (WBHE) technology. Unlike in conventional open-loop geothermal systems, heat carrier fluids in closed-loop systems circulate inside WBHEs, with no ground fluids extracted from surrounding rocks.

Despite the recent success of theoretical oilfield geothermal closed-loop system experiments, certain challenges remain for understanding the possibility of large-scale access to geothermal resources in oilfields using closed-loop technologies. Additionally, due to the continuous spatial variability of geological formations associated with deep oil and gas wells in oilfields, the thermophysical parameters of geological strata surrounding the well, as well as the depth and thickness of the strata, must be considered to achieve accurate and realistic estimates of heat exchanger performance.

Given the above considerations, this study aims to contribute to the discussion, encouraging a reflection on the potential benefits and limitations of using low- to medium- 
temperature geothermal energy resources associated with dismissed Italian hydrocarbon wells as a renewable source of energy.

Using the information on Italian hydrocarbon wells and on-field temperatures available from both the National Mining Office of the Italian Ministry for Economic Development (MISE) and the Italian National Geothermal Database, the simplified heat exchange model (coaxial WBHE) described in [13] was applied to three hydrocarbon wells. The main purpose was to properly analyse heat exchange mechanisms in three different Italian oil and gas fields, emphasising that the quantity of the potentially extracted thermal energy can change based on geological and depositional context. Wells from the Villafortuna-Trecate field, the Val d'Agri field and the Gela field were selected.

The assumption that the thermophysical parameters (thermal conductivity, volumetric heat capacity and rock density) are constant values, as described in [13], has been overcome by applying the elaborated model to the detailed stratigraphic data of each case study.

The final use of the potentially extracted heat would be in possible direct applications by means of a cascade plant system, which provides specific thermal energy amounts to production cycles in manufacturing, agricultural and recreational districts near the oilfields. Considering specifically the examples of disused hydrocarbon wells analysed, located in the Italian territory, it is possible to state that they are located far from inhabited areas or buildings: it is therefore not generally possible to hypothesize the use of the extracted thermal energy for heating purposes.

\section{Materials and Methods}

\subsection{Oilfields in Italian Sedimentary Basins}

To introduce the analysis of the selected case studies, this paper provides an overview of the main sedimentary systems and associated hydrocarbon fields.

The Italian landscape is dominated by the Southern Alps and the Apennines mountain chains. The two chains are bordered in their outer margins by well-developed sedimentary foreland basins, especially along the Adriatic sectors, and by relatively wide foreland areas (e.g., the Po Plain, Adriatic Sea and Hyblean Basin). Due to Italy's complex geological and sedimentary history, a variety of petroleum systems have been identified. Authors provided overviews of the Italian peninsula's geological evolution and described how Italian hydrocarbon occurrences can be classified by their association with three main tectono-stratigraphic systems (Figure 1) [14-16]: (1) carbonate Mesozoic substratum of the foredeep/foreland area and of the external thrust belts; (2) thrusted terrigenous OligoMiocene foredeep wedges (Southern Alps, Northern Apennines, Calabria and Sicily); and (3) terrigenous Pliocene-Pleistocene successions of the late foredeep basins of the Apennines, in both the central and northern Adriatic Sea and the Po Plain.

According to [17], at least five important source rocks have been recognised, with ages ranging from the Mesozoic through the Pleistocene. Three of the source rocks were deposited during Mesozoic crustal extension and are mainly oil-prone. Hydrocarbon occurrences associated with these sources are usually found in complex carbonate structures along the Apennines thrust-and-fold belt and in the foreland; the Villafortuna-Trecate (Po Plain), Val d'Agri-Tempa Rossa (southern Apennines) and Gela (Sicily) fields represent the largest oil accumulations pertaining to these systems.

The two other source rocks were deposited in the foredeep terrigenous units of the foreland basins, which formed during the Cenozoic orogenesis. The older of the two sources is thermogenic gas-prone and is found in the highly tectonised Oligo-Miocene foredeep wedges; gas occurrences associated with this source are mainly concentrated along the northern Apennines margin (e.g., the Cortemaggiore field), in Calabria (e.g., the Luna field) and in Sicily (e.g., the Gagliano field). The younger source is biogenic gas-prone and is situated in the outer Plio-Pleistocene foredeeps.

Reference [17] clearly showed the geographic limitation of the oil-prone VillafortunaTrecate Middle Triassic and Val d'Agri-Tempa Rossa Cretaceous systems, as opposed to the 
wide distribution of the Late Triassic-Early Jurassic system and of the biogenic gas-prone Plio-Pleistocene systems (Figure 1).
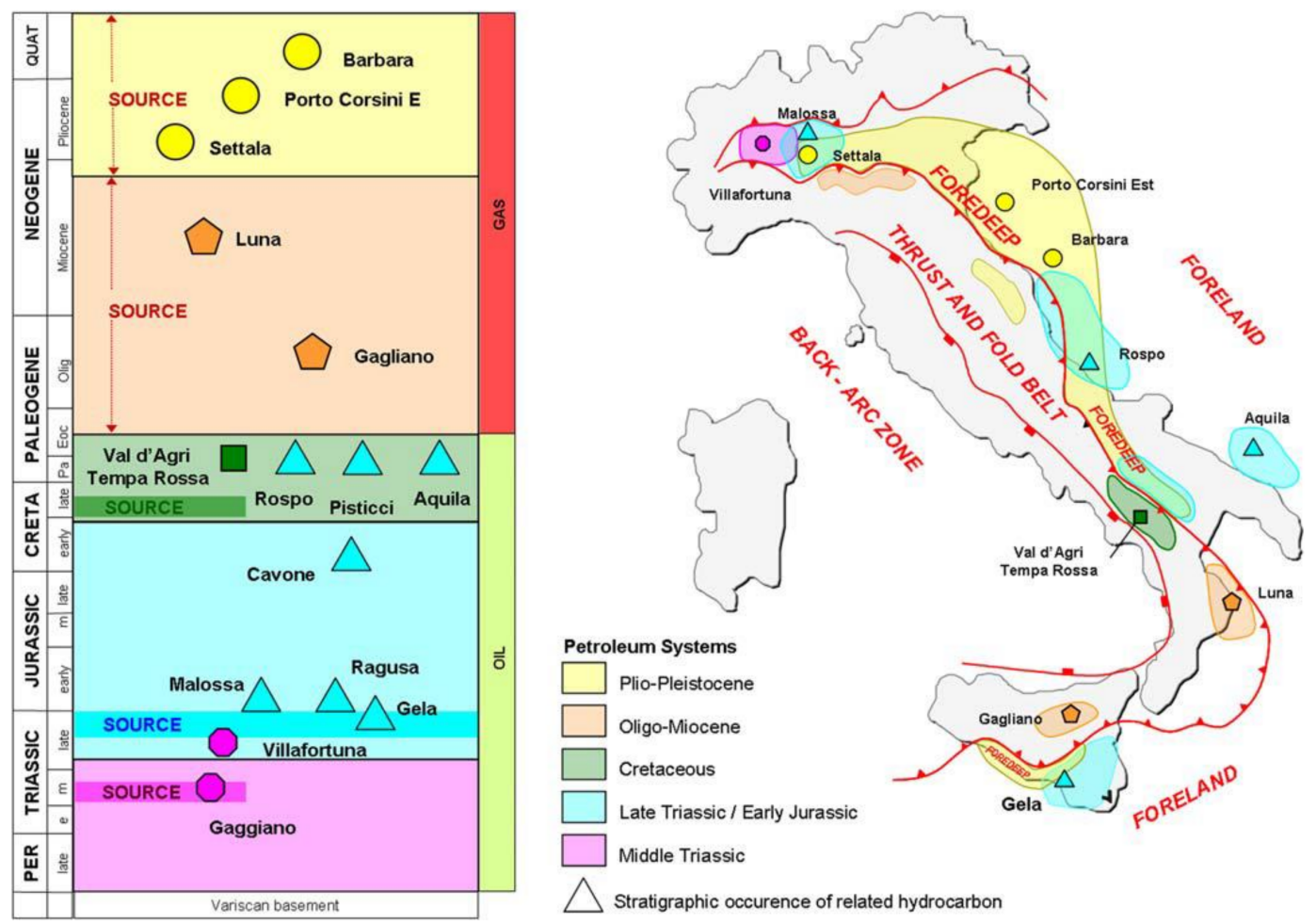

Figure 1. Stratigraphic and geographic location of the Italian petroleum systems [17].

This study focuses on the analysis of geothermal energy potential associated with disused hydrocarbon wells of the different petroleum systems of the Mesozoic carbonate succession. Three deep hydrocarbon wells located inside of the Villafortuna-Trecate oilfield, the Tempa Rossa Field and the Gela Field are discussed in detail.

Detailed information related to the litho-stratigraphic units and temperature data visualisation can be found on The Italian National Geothermal Database (BDNG), the largest collection of Italian geothermal data. BDNG was established in the 1980s and implemented by the Institute of Geosciences and Earth Resources (IGG) of the National Research Council (CNR) of Italy [9].

Information regarding productive and dismissed oil and gas wells in Italy was also provided by the National Mining Office of the Italian Ministry for Economic Development (MISE) and by the website of the VIGOR, promoted by the MISE-DGRME (Direzione Generale Risorse Minerarie ed Energetiche), the Italian Geological Society and the Assomineraria Association.

\subsubsection{The Villafortuna-Trecate Field}

First, data were analysed for the geothermal potential associated with the disused Villafortuna 1 hydrocarbon well, located within the Villafortuna-Trecate oilfield (Figure 1). The Villafortuna-Trecate system represents one of the largest oil accumulations of the Italian Middle Triassic carbonate petroleum system. The petroleum system is wholly developed inside the Triassic succession and consists of two main reservoirs, composed of dolomitised carbonate platform rocks and a set of source rocks deposited in the adjacent anoxic intra-platform basins.

Generally, the depth of the main reservoir associated with the Villafortuna-Trecate field is between $5800 \mathrm{~m}$ and $6100 \mathrm{~m}$ deep, with temperatures of approximately $160-170{ }^{\circ} \mathrm{C}$ [18]. Because of its depth, the main reservoir can be pursued only in the 
outer sector of the foredeeps and in foreland regions (the Piedmont area); areas along the thrust belt (the Po Plain) are generally too deep.

As demonstrated by information related to the litho-stratigraphic units and temperature data visualisation reported in Table 1 and Figure 2, the stratigraphic succession is mainly composed of clastic sedimentary and carbonate rocks. The analysed well has a maximum depth of $6202 \mathrm{~m}$ and temperatures reaching $165^{\circ} \mathrm{C}$.

Table 1. Villafortuna 1 hydrocarbon well-lithostratigraphic profile (Villafortuna Trecate Oilfield, Western Po Plain).

\begin{tabular}{cccccc}
\hline $\begin{array}{c}\text { Depth } \\
\mathbf{m}\end{array}$ & $\begin{array}{c}\text { Litho-Stratigraphic } \\
\text { Formation }\end{array}$ & Age & $\begin{array}{c}\boldsymbol{\lambda}_{\mathbf{s}} \\
\mathbf{W} / \mathbf{m K}\end{array}$ & $\begin{array}{c}\mathbf{\rho c}_{\mathbf{s}} \\
\mathbf{k J} / \mathbf{m}^{\mathbf{3}} \mathbf{K}\end{array}$ & $\begin{array}{c}\boldsymbol{\rho} \\
\mathbf{k g} / \mathbf{m}^{\mathbf{3}}\end{array}$ \\
\hline 609 & $\begin{array}{c}\text { Terrigenous } \\
\text { sedimentary deposits } \\
\text { Fine Sand (dry) }\end{array}$ & $\begin{array}{c}\text { Holocene/Upper } \\
\text { Pleistocene }\end{array}$ & 0.30 & 800 & 1700 \\
\hline 1258 & Sand (dry) & Pleistocene & 0.30 & 800 & 1700 \\
\hline 1405 & Clay Sand & Low Pliocene & 1.61 & 1696 & 1890 \\
\hline 5493 & $\begin{array}{c}\text { Clastic sedimentary } \\
\text { rocks (Sandstone, } \\
\text { Conglomerates and } \\
\text { Silty Marl) }\end{array}$ & $\begin{array}{c}\text { Aquitanian - } \\
\text { Albian }\end{array}$ & 3.16 & 1937 & 2359 \\
\hline 6202 & $\begin{array}{c}\text { Carbonate rocks- } \\
\text { Calcarenite/Dolostone }\end{array}$ & $\begin{array}{c}\text { Low Cretaceous - } \\
\text { Middle Triassic }\end{array}$ & 3.50 & 2010 & 2480 \\
\hline
\end{tabular}

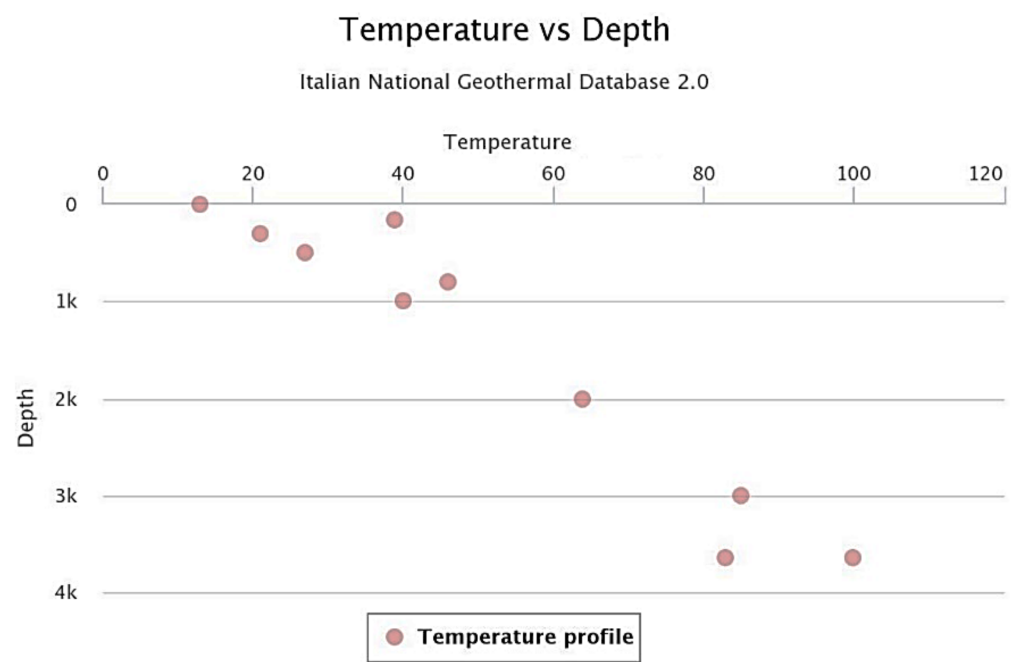

Figure 2. Temperature data visualisation for the Villafortuna 1 hydrocarbon well: Depth (m); Temperature $\left({ }^{\circ} \mathrm{C}\right)$.

\subsubsection{The Val d'Agri-Tempa Rossa Field}

The second case study, the Tempa Rossa 1D hydrocarbon well, is located within the Tempa Rossa oilfield (Figure 1). The Tempa Rossa system lies in the Mesozoic carbonate substratum of the foredeep and foreland areas and in the external thrust belt of the southern Apennines. The system bears the largest oil and gas accumulations in Italy, including the Val d'Agri and Tempa Rossa oil fields.

The reservoirs are composed of fractured limestones from the buried Apulia Platform, which extends from the Cretaceous to the Miocene. The majority of the oil column exceeds $1000 \mathrm{~m}$ and sometimes exceeds $2000 \mathrm{~m}$. The seal is composed of Lower Pliocene shales. The source rocks, identified in a few deep wells of the area, are mainly Albian-Cenomanian and are marine anoxic carbonates facies containing sulphur [19]. 
Unlike the Villafortuna 1 hydrocarbon well, the Tempa Rossa 1D well features lithostratigraphic units mainly composed of sandstone and associated shales (Table 2). The maximum depth of the analysed well is $5042 \mathrm{~m}$; temperatures reach $107^{\circ} \mathrm{C}$ (Figure 3).

Table 2. Tempa Rossa 1D hydrocarbon well-lithostratigraphic profile (Tempa Rossa Field, Western Po Plain).

\begin{tabular}{ccccc}
\hline $\begin{array}{c}\text { Depth } \\
\mathbf{~ m}\end{array}$ & Litho-Stratigraphic Formation & $\begin{array}{c}\lambda_{\mathbf{s}} \\
\mathbf{W} / \mathbf{m K}\end{array}$ & $\begin{array}{c}\mathbf{\rho c}_{\mathbf{s}} \\
\mathbf{k J} / \mathbf{m}^{\mathbf{3}} \mathbf{K}\end{array}$ & $\begin{array}{c}\boldsymbol{\rho} \\
\mathbf{k g} / \mathbf{m}^{\mathbf{3}}\end{array}$ \\
\hline 23 & $\begin{array}{c}\text { Superficial sedimentary deposits } \\
\text { Fine Sand (dry) }\end{array}$ & 0.30 & 800 & 1700 \\
\hline 2912 & $\begin{array}{c}\text { Sandstones interspersed with shale } \\
\text { and clays }\end{array}$ & 3.00 & 1884 & 2330 \\
\hline 5042 & Clays, argillites and calcarenites & 2.34 & 1590 & 1917 \\
\hline
\end{tabular}

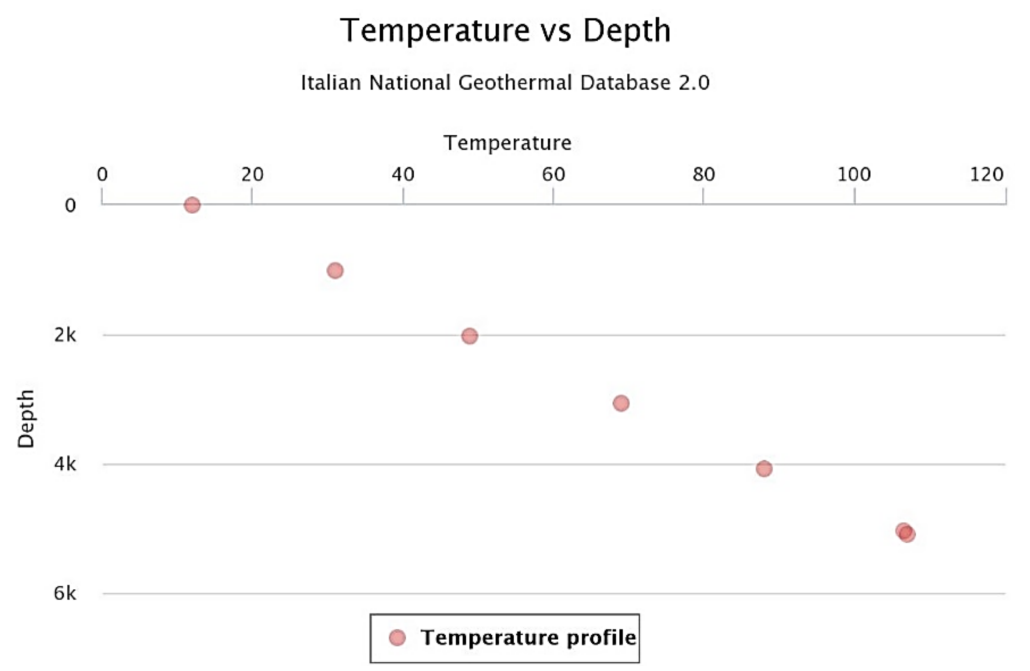

Figure 3. Temperature data visualisation for the Tempa Rossa 1D hydrocarbon well: Depth (m); Temperature $\left({ }^{\circ} \mathrm{C}\right)$.

\subsubsection{The Gela Field}

The third case study is the Gela 38 hydrocarbon well, located in the Gela oilfield in Sicily. The Gela field is part of the Late Triassic-Early Jurassic petroleum system and is linked to the main phase of the Tethyan rifting. It is the most explored of the three systems, both in the foreland and in the thrust belt, and from Lombardy to Sicily. The source rocks are terrigenous or mixed carbonate-terrigenous and were deposited during the anoxic stage that preceded the extension of the Jurassic basins.

The Ragusa-Gela fields were discovered in the 1950s and have been the largest source of Italian oil for some of the past decades. The reservoir is composed of fractured, massive dolomites of the Upper Triassic Gela Formation. The traps are large-scale, probably polyphase anticlines bounded by high-angle normal faults.

Based on the available lithological and temperature data reported in Table 3 and Figure 4, the area's stratigraphic succession is composed of marl, calcareous marl and clays. The well has a maximum depth of $3446 \mathrm{~m}$ and temperatures that reach $85^{\circ} \mathrm{C}$. 
Table 3. Gela 38 hydrocarbon well-lithostratigraphic profile (Gela Field, Sicily).

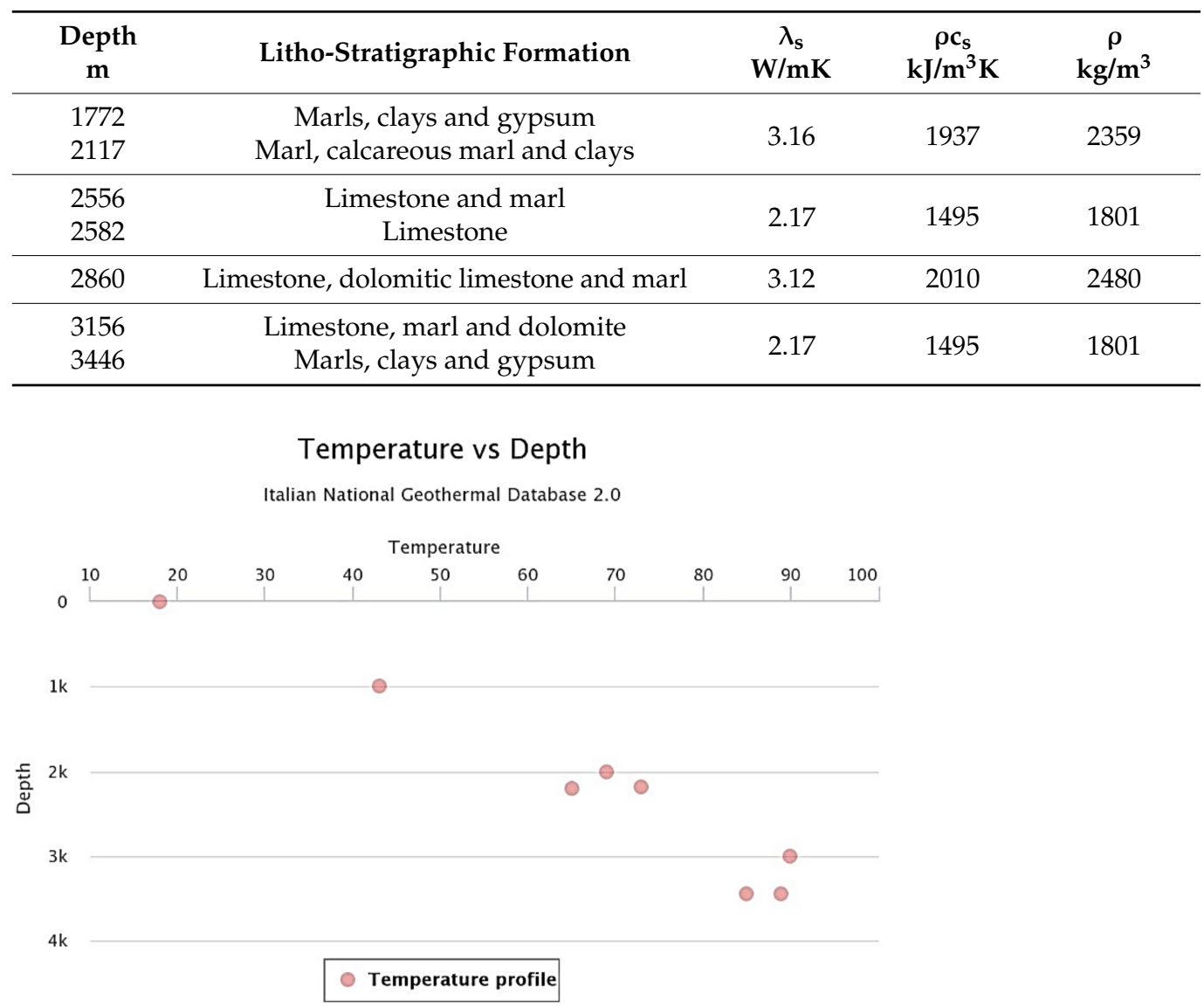

Figure 4. Temperature data visualisation for the Gela 38 hydrocarbon well: Depth (m); Temperature $\left({ }^{\circ} \mathrm{C}\right)$.

\subsection{Closed-Loop Geothermal Energy Systems: WBHEs}

Exploiting the geothermal energy resources associated with decommissioned hydrocarbon wells requires that the borehole to be retrofitted with a heat exchanger. In current practice, two main types of closed-loop systems are used to harness geothermal energy resources by taking advantage of disused boreholes in oilfields: U-tube and coaxial doublepipe WBHE technologies [20,21]. Both kinds of systems allow for the extraction of heat from the ground without extracting or re-injecting any geothermal fluids.

In U-tube heat exchangers, fluid is pumped through one tube string and comes out the other, while coaxial heat exchangers are composed of two concentric pipes, as shown in Figure 5 and Table 4 . In coaxial WBHEs circulating working fluid is injected into the outer pipe (the injection pipe), flows down to the lower part of the exchanger and is gradually warmed by heat from the rocks. After the fluid reaches the bottom hole of the well, it flows upwards through a thinner pipe, which acts as the inner pipe (the extraction pipe). The gap between internal pipes is filled with an insulating material, and the bottom hole is sealed. Heat exchange occurs between the geological formation and the fluid in the injection pipe and between the fluid in the injection pipe and the fluid in the extraction pipe. 

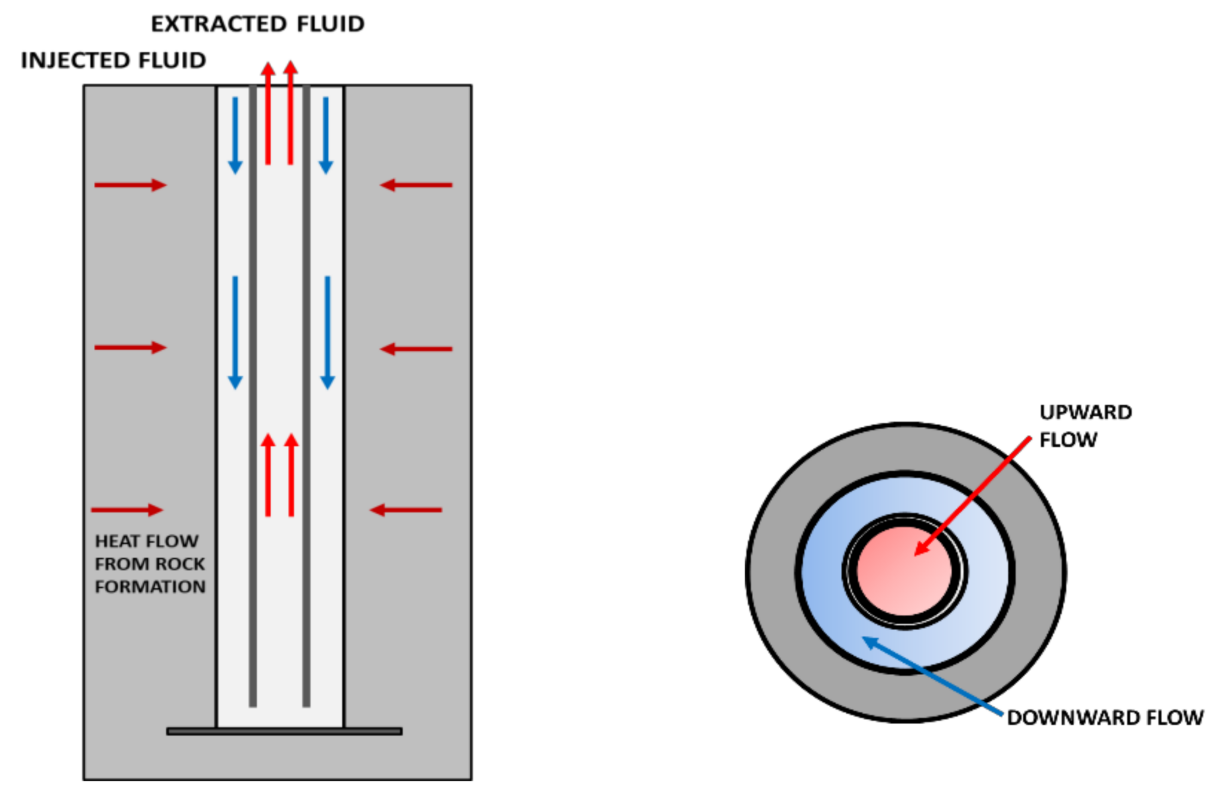

Figure 5. Schematic representation of a coaxial Wellbore Heat Exchanger (WBHE).

Table 4. Coaxial WBHE-geometric parameters.

\begin{tabular}{ccc}
\hline Coaxial Wellbore Heat Exchanger-Geometric Parameters & Symbol & Unit of Measure \\
\hline Outer pipe area & $A_{0}$ & {$\left[\mathrm{~m}^{2}\right]$} \\
\hline Inner pipe area & $A_{i}$ & {$\left[\mathrm{~m}^{2}\right]$} \\
\hline Radius of outside wellbore & $r_{w}$ & {$[\mathrm{~mm}]$} \\
\hline External radius of the external casing & $r_{c}$ & {$[\mathrm{~mm}]$} \\
\hline Internal radius of the external casing & $r_{i}$ & {$[\mathrm{~mm}]$} \\
\hline Radius of the internal casing & $r_{0}$ & {$[\mathrm{~mm}]$} \\
\hline Thicknesses of the pipe exchanger & $d$ & {$[\mathrm{~mm}]$} \\
\hline Depth & $z$ & {$[\mathrm{~m}]$} \\
\hline
\end{tabular}

Corrosion must be considered when selecting this type of system; it may be ideal for heat exchange, but it may also reduce the system's operational life. Due to its low cost and its heat transfer and storage capacity, water is still one of the most commonly used fluids. The operating parameters of subsurface closed-loop systems, such as fluid flow rate and pipe diameter, should be selected to guarantee transient turbulent flow conditions, since these conditions facilitate heat transfer, and low hydraulic head losses, since this indicates lower energy expenditure on circulation pumping.

Compared to U-tube heat exchangers, coaxial heat exchangers have a higher surface area and a higher volume of the working fluid through which heat exchange occurs. As a result, under the same injection rate conditions (q), the fluid flow velocity in the coaxial pipe system and the hydraulic pressure required for fluid circulation can be lower, resulting in decreased energy consumption from pumping [21]. The coaxial geometry of a doublepipe heat exchanger also has the advantage of reducing thermal resistance between the circulating fluid and the wellbore.

In this paper, in order to evaluate and analyse the temperature profiles of the selected fluid (water) associated with a coaxial double-pipe WBHE technology, the simplified models proposed below were implemented in MATLAB and applied to the selected case studies: the Villafortuna 1, Tempa Rossa 1D and Gela 38 hydrocarbon wells.

For the elaborated model, two main assumptions were considered: the propagation of heat in the reservoir occurs by means of conduction (convection phenomena are neglected), 
and the propagation of heat inside the wellbore tubes takes place through both conduction and convection.

\subsection{Heat Transfer in Coaxial WBHEs}

In coaxial WBHEs, the steel downward tube is cemented to the rock wall and so is in contact with the hole in the well. The energy balance of the fluid in the injection pipe can be expressed with the following equation:

$$
\frac{\partial\left((\rho c)_{f} A_{0} T_{f o}\right)}{\partial \tau}+\frac{\partial\left((\rho c)_{f} A_{0} v_{f} T_{f o}\right)}{\partial z}=-\frac{d Q}{d z}+\frac{d Q_{i 0}}{d z}
$$

where $A_{0}$ and $v_{f}$ are the outer pipe area and fluid velocity, respectively; $T_{f_{0}}$ is the fluid temperature in the outer pipe; and $d Q / d z$ is the heat extraction from the formation at unit well depth $(\mathrm{W} / \mathrm{m})$.

Although insulation is used to prevent heat loss from the inner-pipe fluid, heat is partly transferred between the two pipes, so $d Q_{i o} / d z$ represents the heat flux from the inner pipe to the outer pipe. Therefore, the energy equation for the inner pipe can be given as:

$$
\frac{\partial\left((\rho c)_{f} A_{i} T_{f i}\right)}{\partial \tau}+\frac{\partial\left((\rho c)_{f} A_{i} v_{f} T_{f i}\right)}{\partial z}=-\frac{d Q_{i 0}}{d z}
$$

By assuming steady heat transfer and constant heat flux in wellbore components (e.g., insulation, casing and cement), heat extraction from the formation $d Q / d z$ can be assumed to be equal to the heat flux through the outside surface of the wellbore (interface of the wellbore and rock formation) to the injected fluid [22]:

$$
\frac{d Q}{d z}=2 \pi r_{w} k_{w}\left(T_{f 0}-T_{w}\right)=\left(T_{f 0}-T_{w}\right) / R_{w}
$$

where $T_{w}$ is the temperature at the interface of the wellbore and the formation, $k_{w}$ is the heat transfer coefficient between the outer-pipe fluid and wellbore exterior and $R_{w}$ is the resistance between the outer pipe and surrounding rocks.

At the well bottom, the heated fluid is forced to enter and flow through the internal pipe of the coaxial WBHE. Going up to the wellhead, heat transfer occurs only through the wall of the internal pipe. Thus, $d Q_{i 0} / d z$ is determined by considering the temperature difference between the outer-pipe and inner-pipe fluids, as well as the estimated thermal resistance of the insulation:

$$
\frac{d Q_{i 0}}{d z}=2 \pi r_{0} k_{i 0}\left(T_{f i}-T_{f 0}\right)=\left(T_{f i}-T_{f 0}\right) / R_{i 0}
$$

where $T_{f i}$ is the fluid temperature in the inner pipe, $k_{i 0}$ is the heat transfer coefficient between the outer pipe and inner pipe and $R_{i 0}$ is the thermal resistance between the outer pipe and inner pipe.

\subsubsection{Coaxial WBHE: Coefficient of Heat Exchange between Outer-Pipe Fluid and the} Wellbore Exterior

In an analysis of the energy balance equation for the fluid in the outer pipe (injection pipe) of a coaxial WBHE, a careful estimate of the parameter $k_{w}$ is fundamental for proper evaluation of the heat exchange between the outer-pipe fluid and the drilled geological formations.

For a coaxial WBHE, the heat exchange coefficient for the injection pipe can be expressed as the sum of heat transfer components, expressed in terms of thermal resistance values $\left(R_{w}\right)$ [22]:

$$
R_{w}=R_{s}+R_{a}+R_{c}
$$


where $R_{S}$ is a function of time that represents the thermal resistance due to conductive heat transfer in the rock, $R_{a}$ is the thermal resistance due to convective heat transfer into the pipe and $R_{c}$ is the thermal resistance due to conductive heat transfer through the casings of the well.

In the evaluation of total thermal resistance, the conductive term prevails; consequently, the thermal exchange is directly proportional to the convective transfer coefficient.

Conductive thermal resistance $\left(R_{S}\right)$ can be expressed as follows:

$$
R_{s}=\frac{1}{2 \lambda_{s}} \operatorname{In} \frac{2 \sqrt{\alpha_{s} t}}{r_{w}}
$$

where $\lambda_{s}(\mathrm{~W} / \mathrm{mK})$ is the thermal conductivity of the rock and $\alpha_{s}(\mathrm{~m} / \mathrm{s})$ is the thermal diffusivity of the rock. In Equation (6), the relationship in the numerator of the second term represents the time-dependent radius of the thermal influence of the well $\left(r_{s}\right)$.

Convective thermal resistance $\left(R_{a}\right)$ can be determined by the following equation:

$$
R_{a}=\frac{1}{2 r_{c} h_{f}}
$$

where $r_{c}$ is the external radius of the external casing and $h_{f}$ is the convective heat transfer coefficient, which was calculated by using the Nusselt number $(\mathrm{Nu})$ and a form of the Dittus-Boelter equation that assumes turbulent flow inside the tubes (Reynolds number $\geq$ 104) [23]:

$$
\begin{gathered}
h_{f}=\frac{N u \lambda_{f}}{2 r_{c}} \\
N u=0.023 \operatorname{Re}^{0.8} \operatorname{Pr}^{0.4}
\end{gathered}
$$

with $\operatorname{Pr}=\frac{\rho c_{f} \mu}{\lambda_{f}}$ and $\operatorname{Re}=\frac{\rho v_{f} 2 r_{c}}{\mu}$.

Finally, the thermal resistance to heat conduction through the casings of the well can be determined as follows:

$$
R_{c}=\sum_{i=1}^{n} R_{\lambda i}=\frac{1}{2} \sum_{i=1}^{n} \frac{1}{\lambda_{i}} \operatorname{In} \frac{r_{c, i+1}}{r_{c, i}}
$$

where $\lambda_{i}$ is the thermal conductivity of the rock in correspondence with the different casings of the well. Generally, due to the high thermal conductivity of the steel piping, the total thermal resistance of the casing is negligible compared to the rock thermal resistance [13].

As a result, the heat exchange coefficient $k_{w}$ can be correctly determined as follows:

$$
\frac{1}{k_{w}}=\frac{2 r_{c}}{2 \lambda_{s}} \operatorname{In} \frac{4 \sqrt{\alpha_{s} t}}{2 r_{w}}+\frac{1}{h_{f}}
$$

where $r c=r w$ as the thickness of the external tube is negligible.

2.3.2. Coaxial WBHE: Coefficient of the Heat Exchange between the Outer-Pipe Fluid and the Inner Pipe

Unlike in the injection pipe, the total heat flux in the upward pipe (extraction pipe) is determined by a conductive component of the composite pipe and by two convective components, one on the internal wall and one on the external wall of the WBHE.

Consequently, the total heat exchange coefficient $k_{i 0}$ for the extraction pipe can be calculated as follows:

$$
\frac{1}{k_{i 0}}=\frac{r_{0}}{r_{0+d}} \frac{1}{h_{i}}+r_{0} \sum_{i=1}^{n} \frac{1}{\lambda_{i}} \operatorname{In}\left(\frac{r_{i+1}}{r_{i}}\right)+\frac{1}{h_{0}}
$$


where $r_{0}$ is the radius of the inner pipe, $d$ is the thicknesses of the pipe exchanger, $h_{0}$ and $h_{i}$ are the coefficients of convective heat transfer to the inner and outer wall, respectively, and $\lambda_{i}$ is the thermal conductivity of the pipe material.

\subsection{WBHE Model Assumptions}

MATLAB is a software for numerical and statistical calculations that is written in the C programming language. MATLAB R2018b version was used to perform the analysis of WBHEs by implementing the proposed model, with consideration of the following assumptions and approximations.

The reservoir model was built by assuming a single well-positioned at the centre of a circular reservoir. The temperature profile in the radial direction was assumed to be constant. Therefore, there was no temperature gradient in the annulus or in the inner tube. Due to turbulent flow, enhanced mixing phenomena occurred, decreasing the radial gradient. The temperature changed only in the annulus and in the vertical direction of the inner tube, so the temperature profile was vertically unidirectional.

The properties of the heat-carrier fluid were assumed to be constant. As the fluid used in this study was water $\left(100{ }^{\circ} \mathrm{C}, 2 \mathrm{bar}\right)$, no variations occurred due to pressure or/and temperature gradients.

The model was built under steady-state conditions; there were no temperature variations over time, with each point in the tubes (annulus and inner tube) maintaining the same temperature for the lifecycle of the system. For the elaborations, $r_{c}$ (external radius of the external casing) was considered equal to $r_{w}$ (radius of outside wellbore).

In addition, the model considered the resistance associated with tube thickness to be negligible. The tube material had very high conductivity, so its resistance could be considered small compared to the other resistances in the system. For estimation of the resistance associated with the rock (see Equation (6)), the time value used was 3 years after the starting of the system. This assumption made the method a conservative estimate: the system in the years before (1-2 years) turns out in fact to work better. As consequence, the heat exchange phenomena are bigger with the possibility of causing overestimations.

The proposed model followed the path of the fluid using a step-by-step approach. It considered intervals of length $d z$ in which the inlet and outlet temperatures were calculated by solving the energy balance equation for each volume $d v$. For estimating the energy exchange in the radial direction, the mean value of the temperature in each volume $d v$ was used.

\section{Results and Discussion}

The temperature profiles associated with the analysed coaxial WBHE system configurations were obtained by making use of the specific ground properties of the selected case studies (the Villafortuna 1, Gela 38 and Tempa Rossa 1D hydrocarbon wells). Values relating to the thermal properties of the different rock formations have been attributed in accordance with references [11,12] (Tables 1-3).

For all cases analysed, the flow rate of the fluid and the inlet temperature were first considered as $3 \mathrm{~kg} / \mathrm{s}$ and $50{ }^{\circ} \mathrm{C}$, respectively. This temperature is a typical value for direct applications like production cycles in manufacturing and agricultural districts [2]. Subsequently, an analysis was conducted on the thermovector fluid temperature at the outlet as the inlet flow rate varied.

The sizing of the inner and outer tubes, as well as the final casing size, were fixed according to the values proposed in Figure 6 and Table 5. The thermal conductivity value of the insulating material was set to $0.025 \mathrm{~W} / \mathrm{mK}$. 


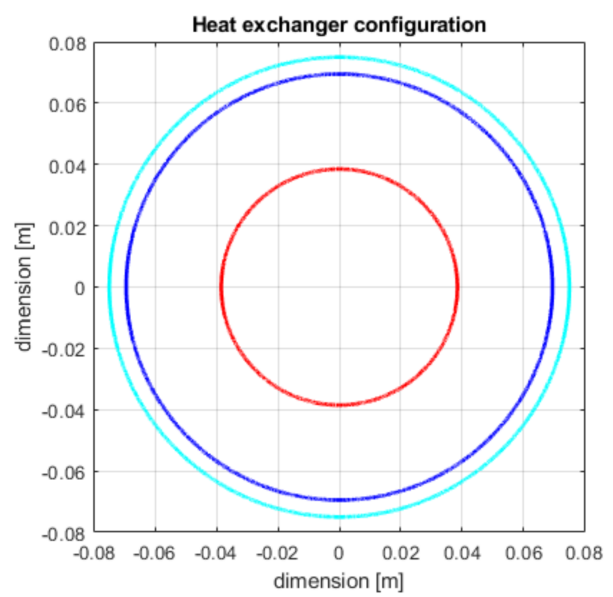

Figure 6. Coaxial WBHE geometry: considered configuration.

Table 5. WBHE tube sizing-ID: internal diameter, OD: external diameter.

\begin{tabular}{ccc}
\hline $\begin{array}{c}\text { Tube Sizing } \\
\mathbf{m}\end{array}$ & $\begin{array}{c}\text { ID } \\
(\mathbf{m m})\end{array}$ & $\begin{array}{c}\text { OD } \\
(\mathbf{m m})\end{array}$ \\
\hline 3 inches & 77.9 & 88.9 \\
\hline 5 inches & 121.4 & 139.7 \\
\hline Casing 7 inches & 150.4 & 177.8 \\
\hline
\end{tabular}

In the first section of an external pipe of a coaxial WBHE system, the downward fluid is in thermal contact with both the ground on one side and the upward tube on the other.

Because of its thermal properties, the ground in contact with the external piping provides a negative heat contribution, while the inner tube of a coaxial WBHE provides a positive one. As the negative contribution is usually larger, the water temperature (working fluid temperature) decreases slightly. This behaviour can be observed by analysing the obtained temperature profiles associated with the Gela 38 and Tempa Rossa 1D hydrocarbon wells, in which the thermovector fluid was cooled at depths of up to $1800 \mathrm{~m}$ and $1200 \mathrm{~m}$, respectively. Unlike in the Gela 38 and Tempa Rossa 1D hydrocarbon wells, the thermovector fluid maintained a constant temperature $\left(50^{\circ} \mathrm{C}\right)$ for the first portion of the borehole $(1400 \mathrm{~m})$ in the Villafortuna 1 hydrocarbon well (Figures 7a, 8a and 9a). The presence of a thick stratigraphic horizon made up of terrigenous sedimentary deposits (Table 1), which are characterised by very low conductivity and specific heat values, negatively influenced the heat exchange and so limited heat dispersion.
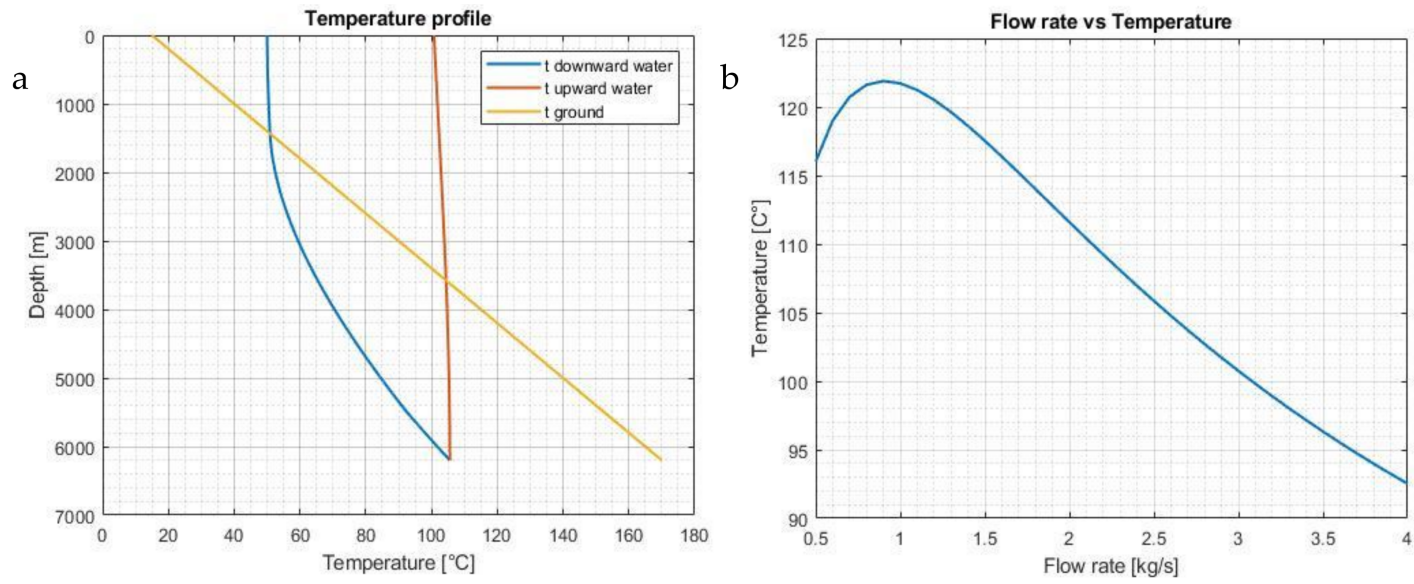

Figure 7. (a) Temperature profile associated with the coaxial WBHE configuration considering the site-specific stratigraphy of Villafortuna 1 well. (b) Wellhead temperature behaviour as the flow rate changes. 

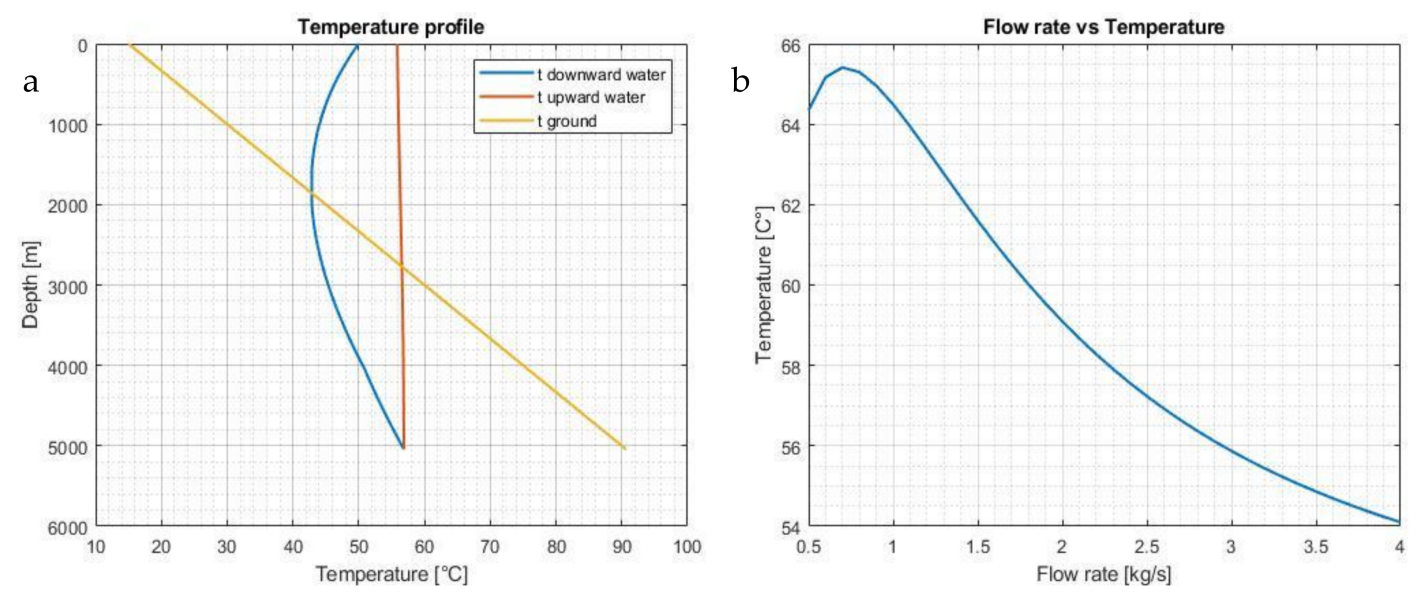

Figure 8. (a). Temperature profile associated with the coaxial WBHE configuration considering the site-specific stratigraphy of Tempa Rossa 1D well. (b) Wellhead temperature behaviour as the flow rate changes.
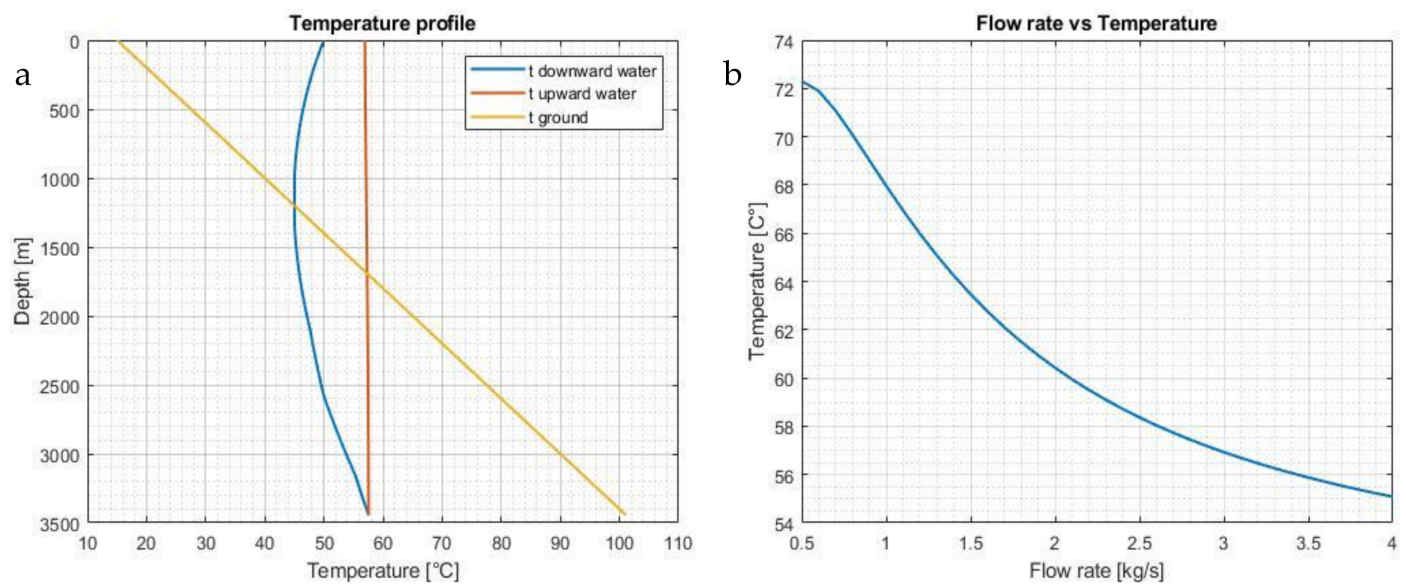

Figure 9. (a) Temperature profile associated with the coaxial WBHE configuration considering the Scheme 38 well. (b) Wellhead temperature behaviour as the flow rate changes.

However, when the water and ground temperatures approached similar values in all three hydrocarbon wells, the negative contribution decreased, and water temperature increased. As the downward water profile line crossed the ground temperature line, the ground's heating process began, and the ground contribution became positive. Due to the presence of the insulating material, the heat exchange coefficient between the annulus and the inner tube was quite low, and the increase in the working fluid temperature could be mainly associated with the contribution of the ground.

Using the fixed inlet working fluid temperature $\left(50^{\circ} \mathrm{C}\right)$ and the estimated fluid temperature at the outlet for the three case studies (Figures 7a, $8 \mathrm{a}$ and $9 \mathrm{a}$ ), thermal power values were evaluated for $627.9 \mathrm{KW}\left(100{ }^{\circ} \mathrm{C}\right.$, Villafortuna 1$), 75.3 \mathrm{KW}\left(56{ }^{\circ} \mathrm{C}\right.$, Tempa Rossa 1D) and 100.5 KW (58 ${ }^{\circ} \mathrm{C}$, Gela 38).

Considering a cascading exploitation mode of the heat accumulated by the working fluid water in Villafortuna 1 WBHE, it is correctly possible to hypothesize a multi-variant and comprehensive use of the resource. The outflow temperature of geothermal water at the wellhead is $100^{\circ} \mathrm{C}$, which allows it to progressively be used for greenhouse heating $\left(100-80^{\circ} \mathrm{C}\right)$, domestic hot water and food industry $\left(80-70^{\circ} \mathrm{C}\right)$, animal breeding $\left(60^{\circ} \mathrm{C}\right)$, biomass and agricultural culture $\left(50^{\circ} \mathrm{C}\right)$. On the contrary, the thermal load accumulated in correspondence with Tempa Rossa 1D and Gela 38 wells turns out to be sufficient neither to justify the costs of plant retrofitting nor to plan a cascading exploitation of the geothermal fluid produced. 
As can be seen in Figures $7 b, 8 b$ and $9 b$, the inlet flow rate strongly influenced the temperature of the wellhead thermal fluid. In each case, it is possible to identify an inlet flow rate value $(\mathrm{kg} / \mathrm{s})$ in order to obtain a higher fluid temperature at the outlet and optimize the quantity of extracted thermal power. When considering inlet flow rate values between 0.5 and $0.8 \mathrm{~kg} / \mathrm{s}$, the output fluid temperature increased up to about $122{ }^{\circ} \mathrm{C}$ $(0.8 \mathrm{~kg} / \mathrm{s}$, Villafortuna 1$), 65.5{ }^{\circ} \mathrm{C}\left(0.7 \mathrm{~kg} / \mathrm{s}\right.$, Gela 38) and $72{ }^{\circ} \mathrm{C}(0.5 \mathrm{~kg} / \mathrm{s}$ Tempa Rossa 1D). For higher values, the trend was inverted in all three cases.

However, for coaxial WBHE systems like the one analysed, such low inlet flow rates may not be technically appropriate. The heat-exchange modalities are in fact not the only aspect that must be considered to carry out the correct analysis of the heat transfer mechanisms associated with coaxial WBHE. Pressure loss phenomena need to be analysed as they affect pumping costs and are not negligible in the management of a closed-loop geothermal system. In coaxial WBHE, the inlet flow rate strongly influences the temperature of the wellhead thermal fluid. As pressure losses are proportional to the velocity, an increase in the inlet flow rate values will cause an increase in the required pumping power.

\section{Conclusions}

Over time, the petroleum systems in Italian sedimentary basins have been explored for oil and gas extraction. Since 1985, 7246 wells have been drilled for hydrocarbon extraction. Of these, 898 wells are located onshore with various operational statuses. Geological and geophysical exploration campaigns have ascertained the coexistence of low- to medium-temperature geothermal energy resources in the deepest regions of such geological contexts. As such, energy production based on the exploitation of available lowto medium-temperature geothermal resources associated with disused deep oil and gas wells in Italian oilfields could represent a considerable source of renewable energy.

This study used information on Italian hydrocarbon wells and on-field temperatures to apply a simplified coaxial WBHE model to three hydrocarbon wells. The main purpose was to analyse heat exchange mechanisms in three different Italian oil and gas fields (the Villafortuna-Trecate, Val d'Agri and Gela fields), emphasizing differences in the quantity of extracted thermal energy and considering different geological and depositional contexts.

All calculations considered the detailed stratigraphic data and related thermophysical parameters (e.g., thermal conductivity, volumetric heat capacity and rock density) of each case study. The results indicate a substantial difference in the potential amount of extracted thermal energy between analysed sites, located in different Italian sedimentary contexts. With a fixed inlet working fluid flow rate of $3 \mathrm{~kg} / \mathrm{s}$ and a fixed temperature of $50{ }^{\circ} \mathrm{C}$, thermal power values were evaluated at $627.9 \mathrm{KW}$ for Villafortuna 1, 75.3 KW for the Tempa Rossa 1D well and 100.5 KW for the Gela 38 hydrocarbon well. The Villafortuna 1 WBHE recorded a maximum extracted fluid temperature of $100^{\circ} \mathrm{C}$, which allows us to hypothesize a cascading exploitation mode of the heat accumulated. Unlike Villafortuna 1, Tempa Rossa and Gela fields had thermal load values that would be of no practical use. As such, the implementation of a coaxial borehole heat exchanger in a such hydrocarbon well may not be energetically or economically worthwhile.

Improving the accuracy of the proposed models by means of future analysis is required: the basic assumption related to the constancy of the properties of the water as working fluid must be overcome by properly analysing the possibility of having phase change (evaporation) in the well, which would change the proposed models. The role in heat transfer and performance of extracting heat from abandoned wells of intraformational flows also needs to be properly considered.

Despite the above considerations, the analysis approach with the associated simplified model proposed in this paper could represent a useful simplified methodological tool to allow the preliminary definition of the possibility of a selected Italian hydrocarbon well to be converted into a geothermal one by means of a coaxial-WBHE technology.

After a preliminary analysis about the presence of industries and agricultural districts, it will be useful to produce a detailed evaluation of the industrial plants available in the 
area near the Villafortuna 1 well: a technical feasibility and cost-benefit analysis of the selected configuration in this proposed case study could represent the subject of future research work.

Author Contributions: All the authors conceived the research work aim; all the authors contributed in finding materials and analysis tools. All authors have read and agreed to the published version of the manuscript.

Funding: This research received no external funding.

Institutional Review Board Statement: Not applicable.

Informed Consent Statement: Not applicable.

Data Availability Statement: Information related to Italian hydrocarbon wells and temperature data are available at the web page of the National Mining Office of the Italian Ministry for Economic Development (MISE) and the Italian National Geothermal Database.

Conflicts of Interest: The authors declare no conflict of interest.

\section{Abbreviations}

\section{Parameter}

Volumetric heat capacity of the fluid

Volumetric heat capacity of the rock

Density

Thermal conductivity of the fluid

Thermal conductivity of the rock

Heat conductivity of the porous media

Heat conductivity of the pipe material

Viscosity

Thermal diffusivity of the rock

Radius of thermal influence

Temperature of the rock

Temperature at the interface of wellbore/formation

Fluid temperature in the outer pipe

Fluid temperature in the inner pipe

Temperature of the environment at the inlet

Temperature of the environment at the surface

Time

Flow rate

Fluid velocity

Heat transfer coefficient-outer pipe fluid and wellbore outside

Heat transfer coefficient-the outer pipe and inner pipe

Convective heat transfer coefficient

Coefficient of convective heat transfer to the inner wall

$\begin{array}{ll}\text { Symbol } & \text { Unit of Measure } \\ \rho c_{\mathrm{f}} & {\left[\mathrm{J} \mathrm{m}^{-3} \mathrm{~K}^{-1}\right]} \\ \rho \mathrm{c}_{\mathrm{s}} & {\left[\mathrm{J} \mathrm{m}^{-3} \mathrm{~K}^{-1}\right]} \\ \rho & {\left[\mathrm{Kgm}^{-3}\right]} \\ \lambda_{\mathrm{f}} & {\left[\mathrm{W} \mathrm{m}^{-1} \mathrm{~K}^{-1}\right]} \\ \lambda_{\mathrm{s}} & {\left[\mathrm{W} \mathrm{m}^{-1} \mathrm{~K}^{-1}\right]} \\ \lambda_{\mathrm{m}} & {\left[\mathrm{W} \mathrm{m}^{-1} \mathrm{~K}^{-1}\right]} \\ \lambda_{\mathrm{i}} & {\left[\mathrm{W} \mathrm{m}^{-1} \mathrm{~K}^{-1}\right]} \\ \mu & {\left[\mathrm{kgm}^{-1} \mathrm{~s}^{-1}\right]} \\ \alpha_{\mathrm{s}} & {\left[\mathrm{ms}^{-1}\right]} \\ \mathrm{r}_{\mathrm{s}} & {\left[\mathrm{m}^{\circ}\right]} \\ \mathrm{T} & {\left[{ }^{\circ} \mathrm{C}\right]} \\ \mathrm{T}_{\mathrm{W}} & {\left[{ }^{\circ} \mathrm{C}\right]} \\ \mathrm{T}_{\mathrm{fo}} & {\left[{ }^{\circ} \mathrm{C}\right]} \\ \mathrm{T}_{\mathrm{fi}} & {\left[{ }^{\circ} \mathrm{C}\right]} \\ \mathrm{T}_{\mathrm{ei}} & {\left[{ }^{\circ} \mathrm{C}\right]} \\ \mathrm{T}_{\mathrm{es}} & {\left[{ }^{\circ} \mathrm{C}\right]} \\ \mathrm{t} & {[\mathrm{h}]} \\ \mathrm{q} & {\left[\mathrm{m}^{3} \mathrm{~h}^{-1}\right]} \\ \mathrm{v}_{\mathrm{f}} & {\left[\mathrm{ms}^{-1}\right]} \\ \mathrm{k}_{\mathrm{w}} & {\left[\mathrm{Wm}^{-2} \mathrm{~K}^{-1}\right]} \\ \mathrm{k}_{\mathrm{i} 0} & {\left[\mathrm{Wm}^{-2} \mathrm{~K}^{-1}\right]} \\ \mathrm{h}_{\mathrm{f}} & {\left[\mathrm{m}^{-2} \mathrm{~K}^{-1}\right]} \\ \mathrm{h}_{0} & {\left[\mathrm{Wm}^{-2} \mathrm{~K}^{-1}\right]}\end{array}$

\section{References}

1. Stephenson, M.H.; Ringrose, P.; Geiger, S.; Bridden, M.; Schofield, D. Geoscience and decarbonization: Current status and future directions. Pet. Geosci. 2019, 25, 501-508. [CrossRef]

2. Kaczmarczyk, M.; Tomaszewska, B.; Operacz, A. Sustainable Utilization of Low Enthalpy Geothermal Resources to Electricity Generation through a Cascade System. Energies 2020, 13, 2495. [CrossRef]

3. Busby, J. Geothermal energy in sedimentary basins in the UK. Hydrogeol. J. 2014, 22, 129-141. [CrossRef]

4. Gascuel, V.; Bédard, K.; Comeau, F.A.; Raymond, J.; Malo, M. Geothermal resource assessment of remote sedimentary basins with sparse data: Lessons learned from Anticosti Island, Canada. Geotherm. Energy 2020, 8, 1-32. [CrossRef]

5. Nasr, M.; Raymond, J.; Malo, M.; Gloaguen, E. Geothermal potential of the St. Lawrence Lowlands sedimentary basin from well $\log$ analysis. Geothermics 2018, 75, 68-80. [CrossRef]

6. Soldo, E.; Alimonti, C.; Scrocca, D. Geothermal Repurposing of Depleted Oil and Gas Wells in Italy. Proceedings 2020, 58, 9. [CrossRef]

7. Cataldi, R.; Mongelli, F.; Squarci, P.; Taffi, L.; Zito, G.; Calore, C. Geothermal ranking of Italian territory. Geothermics 1995, 24, 115-129. [CrossRef] 
8. Montanari, D.; Minissale, A.; Doveri, M.; Gola, G.; Trumpy, E.; Santilano, A.; Manzella, A. Geothermal resources within carbonate reservoirs in western Sicily (Italy): A review. Earth Sci. Rev. 2017, 169, 180-201. [CrossRef]

9. Trumpy, E.; Manzella, A. Geothopica and the interactive analysis and visualization of the updated Italian National Geothermal Database. Int. J. Appl. Earth Obs. Geoinf. 2017, 54, 28-37. [CrossRef]

10. Trumpy, E.; Botteghi, S.; Caiozzi, F.; Donato, A.; Gola, G.; Montanari, D.; Pluymaekers, M.P.D.; Santilano, A.; Van Wees, J.D.; Manzella, A. Geothermal potential assessment for a low carbon strategy: A new systematic approach applied in southern Italy. Energy 2016, 103, 167-181. [CrossRef]

11. Di Sipio, E.; Galgaro, A.; Destro, E.; Giaretta, A.; Chiesa, S.; Manzella, A. Thermal Conductivity of Rocks and Regional Mapping. In Proceedings of the European Geothermal Congress 2013, Pisa, Italy, 3-7 June 2013.

12. Pasquale, V.; Gola, G.; Chiozzi, P.; Verdoya, M. Thermophysical properties of the Po Basin rocks. Geophys. J. Int. 2011, 186, 69-81. [CrossRef]

13. Alimonti, C.; Soldo, E. Study of geothermal power generation from a very deep oil well with a wellbore heat exchanger. Renew. Energy 2016, 86, 292-301. [CrossRef]

14. Bertello, F.; Fantoni, R.; Franciosi, R. Overview of the Italy's Petroleum Systems and Related Oil and Gas Occurrences. In Proceedings of the 70th EAGE Conference and Exhibition Incorporating SPE EUROPEC 2008, Rome, Italy, 9 June 2008; European Association of Geoscientists \& Engineers: Houten, The Netherlands, 2008; Volume 1, pp. 74-78. [CrossRef]

15. Cazzola, A.; Fantoni, R.; Franciosi, R.; Gatti, V.; Ghielmi, M. From thrust and fold belt to foreland basins: Hydrocarbon exploration in Italy, AAPG. Int. Conf. 2011, 10374, 2-5.

16. Fantoni, R.; Galimberti, R.; Ronchi, P.; Scotti, P. Po Plain Petroleum Systems: Insights from Southern Alps Outcrops (Northern Italy). Search Discov. Artic. 2011, 20120, 7.

17. Bertello, F.; Fantoni, R.; Franciosi, R.; Gatti, V.; Ghielmi, M.; Puglise, A. From thrust-and-fold belt to foreland: Hydrocarbon occurrences in Italy. Pet. Geol. Conf. Proc. 2010, 7, 113-126. [CrossRef]

18. Bello, M.; Fantoni, R. Deep oil plays in Po Valley: Deformation and Hydrocarbon Generation in a Deformed Foreland. In Proceedings of the AAPG Hedberg Conference "Deformation History, Fluid Flow Reconstruction and Reservoir Appraisal in Foreland Fold and Thrust Belts", Sicily, Italy, 14-18 May 2002; Palermo e Mondello: Sicily, Italy, 2002; Volume 14, p. 18.

19. Cazzini, F.F. The history of the upstream oil and gas industry in Italy. Geol. Soc. Lond. Spec. Publ. 2018, 465, 243-274. [CrossRef]

20. Lo Russo, S.; Gizzi, M.; Taddia, G. Abandoned oil and gas wells exploitation by means of closed-loop geothermal systems: A review. Geoing. Ambient. E Min. 2020, 160, 3-11. [CrossRef]

21. Wang, K.; Yuan, B.; Ji, G.; Wu, X. A comprehensive review of geothermal energy extraction and utilization in oilfields. J. Pet. Sci. Eng. 2018, 168, 465-477. [CrossRef]

22. Nian, Y.-L.; Cheng, W.-L. Evaluation of geothermal heating from abandoned oil wells. Energy 2018, 142, 592-607. [CrossRef]

23. Davis, A.P.; Michaelides, E.E. Geothermal power production from abandoned oil wells. Energy 2009, 34, 866-872. [CrossRef] 